\title{
Public Health Implications of Solar UV Exposure during Extreme Cold and Hot Weather Episodes in 2018 in Chilton, South East England
}

\author{
Rebecca Rendell (D), Michael Higlett (D), Marina Khazova, and John O'Hagan \\ Public Health England, Chilton, Didcot OX11 ORQ, UK \\ Correspondence should be addressed to Rebecca Rendell; becky.rendell@phe.gov.uk
}

Received 11 June 2019; Revised 26 November 2019; Accepted 20 December 2019; Published 24 January 2020

Academic Editor: Pam R. Factor-Litvak

Copyright (c) 2020 Rebecca Rendell et al. This is an open access article distributed under the Creative Commons Attribution License, which permits unrestricted use, distribution, and reproduction in any medium, provided the original work is properly cited.

\begin{abstract}
Consideration of the implications of solar UV exposure on public health during extreme temperature events is important due to their increasing frequency as a result of climate change. In this paper public health impacts of solar UV exposure, both positive and negative, during extreme hot and cold weather in England in 2018 were assessed by analysing environmental variations in UV and temperature. Consideration was given to people's likely behaviour, the current alert system and public health advice. During a period of severe cold weather in February-March 2018 UV daily doses were around 25-50\% lower than the long-term average (1991-2017); however, this would not impact on sunburn risk or the benefit of vitamin D production. In spring 2018 unseasonably high temperatures coincided with high UV daily doses (40-75\% above long-term average) on significant days: the London Marathon (22 April) and UK May Day Bank Holiday weekend, which includes a public holiday on the Monday (5-7 May). People were likely to have intermittent excess solar UV exposure on unacclimatised skin, causing sunburn and potentially increasing the risk of skin cancers. No alerts were raised for these events since they occurred outside the alerting period. During a heat-wave in summer 2018 the environmental availability of UV was high-on average of $25 \%$ above the long-term average. The public health implications are complex and highly dependent on behaviour and sociodemographic variables such as skin colour. For all three periods Pearson's correlation analysis showed a statistically significant $(p<0.05)$ positive correlation between maximum daily temperature and erythema-effective UV daily dose. Public health advice may be improved by taking account of both temperature and UV and their implications for behaviour. A health impact-based alert system would be of benefit throughout the year, particularly in spring and summer.
\end{abstract}

\section{Introduction}

It is known that climate change is resulting in increased frequency of hot weather episodes [1-4]. Cold weather episodes are also set to continue, although they are predicted on average to reduce in frequency and severity $[1,5]$. These periods of extreme temperatures are likely to significantly impact public health [6-14]; however, little has been said regarding how these events may be affecting people's exposure to solar UV radiation.

Terrestrial solar ultraviolet (UV) radiation, comprising both UV-B (280-315 nm) and UV-A (315-400 nm), has a significant impact on health [15]. It is well established that too much exposure is damaging to the skin and eyes and increases the risk of skin cancers [16-20]. However, exposure to solar UV-B benefits vitamin D production and bone health $[21,22]$; there is emerging evidence of the role of UV$\mathrm{A}$ in cardiovascular health $[15,18,23-32]$, and there are suggestions that solar UV exposure reduces the risk of some cancers and other causes of death [18, 33-35]. In addition, solar radiation exposure as a whole, through exposure to visible radiation $(400-700 \mathrm{~nm})$, plays an important role in melatonin regulation for better quality sleep and serotonin regulation for improved mental health-both of which may enhance length and quality of life [23]. Too little as well as too much exposure to the sun and to solar UV in particular 
can be detrimental to health and result in a burden on the UK health services $[18,36]$.

There is a perception among the public that solar UV and temperature are directly related $[37,38]$. However, there are significant differences in the variation of UV and temperature over the course of the day and year and they are affected by different atmospheric variables (such as ozone, clouds, aerosols and humidity). With climate change, temperatures are unequivocally expected to increase [1-4]. In contrast, future terrestrial UV levels are largely unknown and the trends are difficult to predict [39-42].

People's solar UV exposures are dependent on both the environmental availability of solar UV radiation and behaviour; the latter is likely to be governed by ambient temperature $[43,44]$.

In this paper solar UV doses are assessed in the context of extreme cold and hot weather periods in 2018 in Chilton, South East England. The implications of these periods for public health in terms of sun exposure are assessed with regard to the extreme temperatures experienced and people's likely behaviour, the current UK alert system and public health advice.

\section{Methods}

2.1. Data Collection. Erythema effective UV ( $\left.U_{\text {ery }}\right)$ dose $[20,45,46]$ has been chosen to assess health impacts from exposure to solar UV radiation. Erythema effective UV [45] is an indicator of the strength of UV for causing sunburn and is weighted highly at the shortest terrestrial UV-B wavelengths. It can be used as an approximation for some health effects that are dependent on the shortest terrestrial UV-B wavelengths including cutaneous vitamin $\mathrm{D}$ generation and increased risk of skin cancers $[47,48]$. These health impacts are dependent on dose $[20,49]$. The particular units chosen for this analysis are standard erythemal dose (SED) which is $100 \mathrm{Jm}^{-2}$ erythema effective UV irradiance. The dose required to produce sunburn is dependent on skin type; 2 SED is likely to elicit erythema in a very sensitive skin type (Fitzpatrick skin type I), whereas higher skin types (Fitzpatrick skin type $\mathrm{V}$ or $\mathrm{VI}$ ) may require 20 SED to develop erythema $[19,50]$.

$\mathrm{UV}_{\text {ery }}$ dose has been analysed using data from the Chilton $\left(1^{\circ} 19^{\prime} \mathrm{W}, 51^{\circ} 35^{\prime} \mathrm{N}\right)$ site in the Public Health England (PHE) solar network which has data going back to 1991 $[51,52]$. Data are from ground-based Robertson-Berger Solar Light detectors (Solar Light Co., Philadelphia, USA) which have a spectral response that approximates to the erythema action spectrum [45, 51-53]. Daily doses were calculated by cropping the data on each day from $30 \mathrm{~min}$ before sunrise to $30 \mathrm{~min}$ after sunset, with these sunrise and sunset times provided by the US Naval Observatory website [54]. 2018 data were compared with the 1991-2017 average for each day. Consideration has also been given to the UV Index (UVI) [55], the $\mathrm{UV}_{\text {ery }}$ dose rate, from the same dataset. The highest UVI in the UK is normally about 8 [56].

Daily maximum Central England Temperature (CET) $[57,58]$, provided by the Met Office, the national weather service for the UK, has been chosen as the measure of temperature for this analysis. CET is a dataset of daily temperature data for an area of England enclosed by London $\left(0^{\circ} 8^{\prime} \mathrm{W}, 51^{\circ} 30^{\prime} \mathrm{N}\right)$, Lancashire $\left(2^{\circ} 42^{\prime} \mathrm{W}, 53^{\circ} 46^{\prime} \mathrm{N}\right)$, and Bristol $\left(2^{\circ} 35^{\prime} \mathrm{W}, 51^{\circ} 27^{\prime} \mathrm{N}\right)$ [59] which covers Chilton.

Detailed diurnal variations in ambient temperature were measured using a Davis Vantage Pro2 Weather Station colocated with the solar UV monitoring instrument at Chilton.

2.2. Statistics. Pearson's correlation coefficient analysis was chosen as the most suitable method to assess the relationship between $\mathrm{UV}_{\text {ery }}$ daily dose and daily maximum temperatures. Correlations were considered statistically significant at $p<0.05$.

\section{Results and Discussion}

3.1. 1991-2019 Baseline. The long-term (1991-2017) average daily maximum temperature per month varied from $7.3-$ $7.9^{\circ} \mathrm{C}$ in winter (December-February) to $19.1-21.3^{\circ} \mathrm{C}$ in summer (June-August). The long-term monthly average $\mathrm{UV}_{\text {ery }}$ daily dose over the same period varied from 1.1 SED in December to 29.1 SED in June. The peak $U_{\text {ery }}$ daily dose at Chilton occurred in late June and the peak maximum daily temperature occurred around 1 month later towards the end of July (see Figure 1).

Intra-annual variability is significant in England. The weather is variable and frequently cloudy with usually only a few completely clear days each year [56]. These weather conditions impact both UV and temperature. UV is also affected by total column ozone, which absorbs UV radiation $[46,60]$. Ozone has an annual cycle over England with high variability in spring leading to the possibility of low ozone, and therefore high UV, events at this time of year [61]. Total column ozone is generally relatively stable in summer and autumn.

In order to protect the public from harm to health from cold and hot weather, England has two frameworks in place-the Cold Weather Plan for England [62] and Heat Wave Plan for England [63]. These are supported by an alert system, delivered by the UK Met Office in partnership with PHE, which raises cold weather alerts (CWA) and heat-wave alerts (HWA) based on temperature thresholds (see Table 1). Alerts are not triggered outside their respective alert periods apart from in exceptional circumstances. Public health advice and actions in the plans are triggered at each alert level. These levels comprise: level 1, which applies throughout the alert period; level 2, which means a trigger threshold is forecast; level 3, which means a trigger threshold has been reached; and level 4, which is raised by the government and means the hot or cold weather is very severe and is affecting sectors other than health. Consideration is being given to updating this alert system to make it impact-based [64].

The Heat Wave Plan for England focuses on temperature but also gives consideration to UV exposure by providing advice on sun protection during extreme hot weather. However, the alert period during which actions from this plan can be triggered is centred on peak annual temperature, 


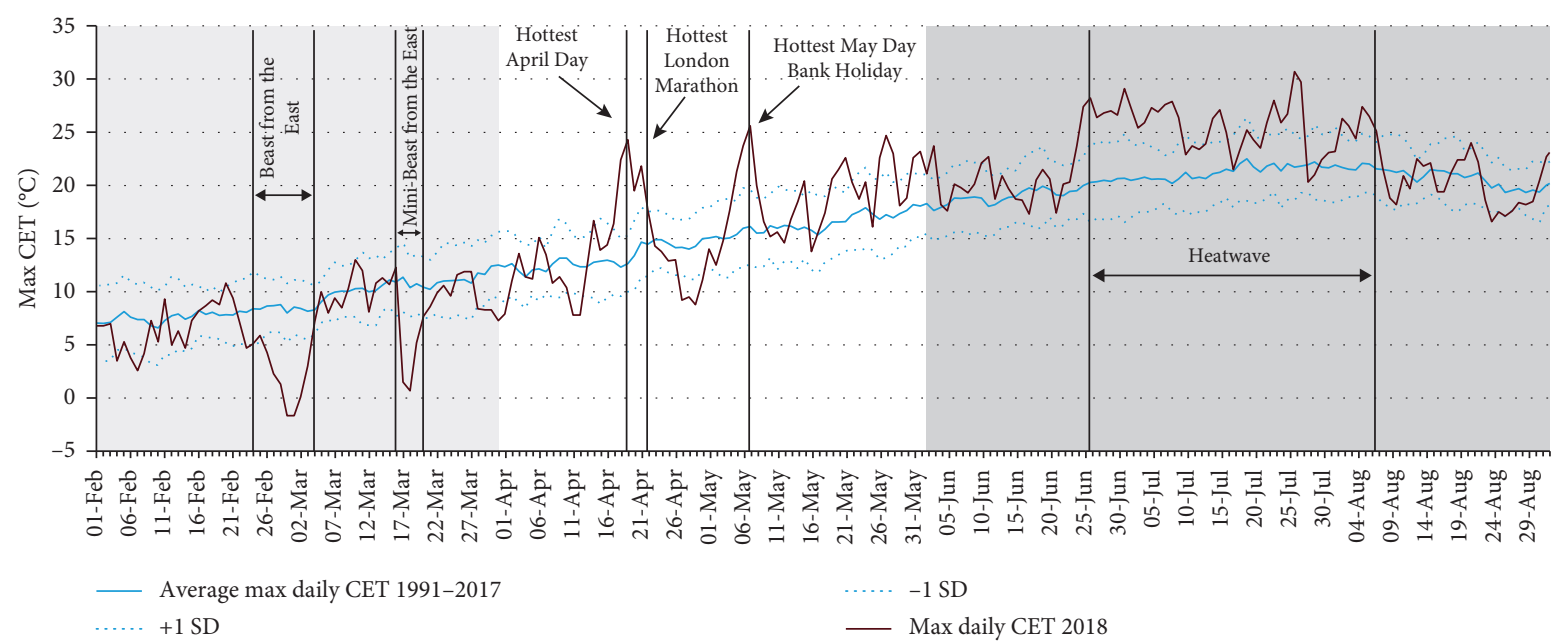

(a)

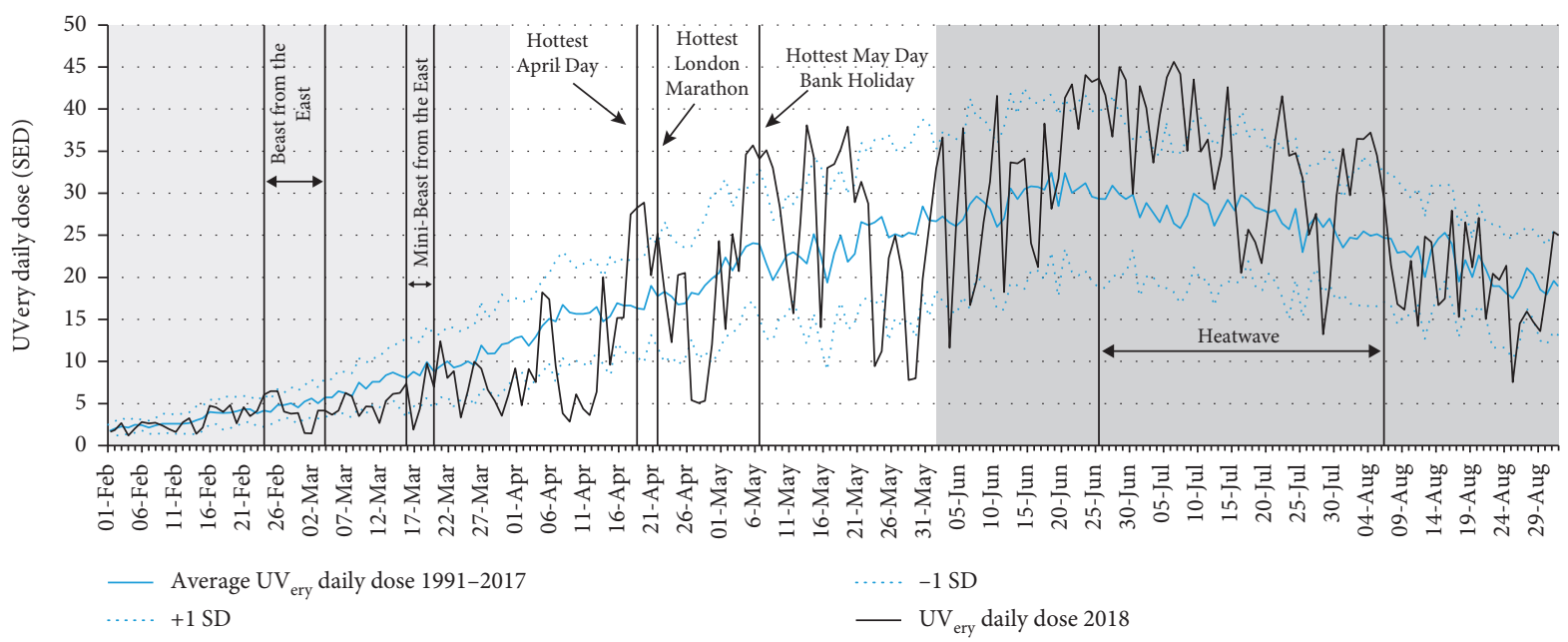

(b)

FIgURE 1: Maximum Central England Temperature (CET) and erythema effective UV, UV ery, daily dose in 2018 in comparison with 1991-2017 average. Dotted lines show \pm 1 standard deviation (SD). Cold weather alert (CWA) period shaded in light grey and heat-wave alert (HWA) period shaded in darker grey.

TABLE 1: Cold weather alert (CWA) and heat-wave alert (HWA) periods and trigger thresholds.

\begin{tabular}{ccc}
\hline & Alert period & Trigger threshold \\
\hline CWA & 1 November-31 March & $\begin{array}{c}2^{\circ} \mathrm{C} \text { mean temperature forecast to last } 48 \mathrm{~h} \text { and/or } \\
\text { severe snow and ice }\end{array}$ \\
HWA & 1 June-15 September & $\begin{array}{c}\text { Maximum daytime temperature of } 30^{\circ} \mathrm{C} \text { and } \\
\text { a minimum night-time temperature of } 15^{\circ} \mathrm{C} \text { for at } \\
\text { least } 2 \text { consecutive days (on average-varies by region) }\end{array}$ \\
\hline
\end{tabular}

while UV daily dose reaches its peak about 1 month earlier. This means that a period of time where UV levels can be high and people may benefit from this public health advice may be missed.

3.2. 2018 England Weather Events. In 2018 there were periods of extreme cold and extreme hot weather; record breaking temperatures were reached multiple times over the course of the year [65]. The dates of these significant cold and hot weather episodes along with their relevant alerts are provided in Table 2.

Figure 1 shows the variation in daily maximum temperature and $\mathrm{UV}_{\text {ery }}$ dose for February-August 2018 with the dates of the extreme weather events indicated. It can be seen that where maximum daily temperature is significantly low or high, often this coincides with, respectively, low or high UV.

Pearson's correlation analysis showed that all three periods had a statistically significant $(p<0.05)$ positive correlation between daily maximum temperature and $U_{\text {ery }}$ 
TABle 2: Significant weather events in South East England in 2018.

\begin{tabular}{|c|c|c|}
\hline Event & Dates & Alerts in South East England \\
\hline Beast from the East & & Level 3 CWA \\
\hline Severe cold and wintry weather & 23 February-4 March 2018 & (trigger threshold reached) \\
\hline Mini-beast from the East & & Level 3 CWA \\
\hline Cold and wintry weather & 16-20 March 2018 & (trigger threshold reached) \\
\hline Start of April & & Level 2 CWA* $^{*}$ \\
\hline Cold weather & 1-4 April 2018 & (trigger threshold forecast) \\
\hline Hottest April day on record & 19 April 2018 & None* \\
\hline Hottest London Marathon & 22 April 2018 & None* \\
\hline Hottest May Day Bank Holiday** & 7 May 2018 & None* \\
\hline 2018 Heat Wave & & Level 2/3 HWA \\
\hline Prolonged hot weather & 26 June-7 August 2018 & (trigger threshold forecast/trigger threshold reached) \\
\hline
\end{tabular}

*Outside the cold weather alert (CWA) and heat-wave alert (HWA) periods. ${ }^{* *}$ UK public holiday on the first Monday in May.

dose for each of the extreme event periods, as shown in Figure 2. In spring the correlation was strong $(r=0.87$, $p<0.0001)$. The Beast from the East period and the Heat Wave period had moderate correlations $(r=0.43, p<0.05$ and $r=0.51, p<0.001$, respectively) and some outlying points can be observed.

In the following sections the implications of these results for public health for each of the three extreme event periods are discussed.

3.3. February-March 2018. In late February and early March, there was a period of severe cold and wintry weather referred to by the media as the Beast from the East. There was another period of less severe cold and wintry weather in mid-March referred to as the mini-beast from the East. During these periods, the maximum daily temperature dropped to $-1.3^{\circ} \mathrm{C}, 116 \%$ (3.4 SD) below long-term average and $0.7^{\circ} \mathrm{C}, 93 \%$ (3.4 SD) below the long-term average, respectively. For most of this period, environmental $\mathrm{UV}_{\text {ery }}$ was $25-50 \%$ below the long-term average, reaching a minimum of 1.5 SED (1.9 SD below the long-term average) on 1 March, the lowest on this day since 1991, the start of the dataset (Figure 1). The maximum daily UVI was low (UVI 1-2) throughout the period.

During this period people's exposure to $U_{\text {ery }}$ was likely to be very low due to a combination of environmental and behavioural factors. The environmental availability of $U V_{\text {ery }}$ was generally low, and the extreme cold temperatures [66] were likely to have caused people to stay indoors for longer $[36,67,68]$ and cover up outside with less than $10 \%$ of skin exposed [43, 44, 69]. This behaviour, staying indoors to keep warm and wrapping up warm when outside, is also part of the public health advice given over this period [62].

This low exposure to $\mathrm{UV}_{\text {ery }}$ would be unlikely to have any noticeable impact on the risk of sunburn or vitamin $\mathrm{D}$ production in comparison with normal conditions for this time of year in England for any skin type [21]. However, it is important to note that $U_{\text {ery }}$ is only one part of the solar spectrum, and sun exposure could have benefits at this time of year such as improved circadian entrainment and may mitigate the excess winter deaths observed each year [62]; this warrants further investigation.
3.4. April-May 2018. During April and May 2018, there were two periods with a concurrent sharp increase in both daily maximum temperatures and $\mathrm{UV}_{\text {ery }}$ dose (Figure 1). From 1 to 19 April maximum daily CET went from $7.9^{\circ} \mathrm{C}$ to $24.3^{\circ} \mathrm{C}$, $36 \%$ (1.3 SD) below to $92 \%$ (4.4 SD) above the long-term average, whilst $\mathrm{UV}_{\text {ery }}$ daily dose went from 9.2 SED to 28.3 SED, $28 \%(-0.8 \mathrm{SD})$ below to $74 \%(+2.1 \mathrm{SD})$ above the longterm average. The maximum UVI increased from 2 to 5 over this period. On 22 April, the hottest London Marathon on record, the $\mathrm{UV}_{\text {ery }}$ daily dose was $25.2 \mathrm{SED},+42 \%$ (+1.2 SD), approaching the highest dose on this day since the start of the dataset in 1991, and the UVI reached 5. From 30 April to 7 May, maximum daily temperatures went from $11.1^{\circ} \mathrm{C}$ to $25.6^{\circ} \mathrm{C},-26 \%(-1.3 \mathrm{SD})$ to $+59 \%(+2.7 \mathrm{SD})$, whilst $\mathrm{UV}_{\text {ery }}$ daily dose went from 12.0 SED to 34.1 SED, $-40 \%$ ( -0.8 SD) to $+42 \%(+1.1 \mathrm{SD})$. The maximum UVI increased from 3 to 6 over this period. The May Day Bank Holiday weekend, which included the hottest May Day Bank Holiday Monday on record, saw $\mathrm{UV}_{\text {ery }}$ daily doses of 34.1-35.7 SED, $+42 \%$ (1.1 $\mathrm{SD})$ to $+48 \%$ (1.7 SD), and the UVI reached 6 on all three days. These events occurred even though there were no low ozone events [61, 70] in spring 2018.

People in England were likely to have been exposed to high doses of solar $\mathrm{UV}_{\text {ery }}$ in spring 2018 due to multiple factors. The environmental availability of $U_{\text {ery }}$ was high on unseasonably warm days, a number of which occurred on nonworking days such as the weekend or a public holiday when people are likely to have spent more time outside [69]. The extended period of cold and wintry weather preceding spring 2018 may have encouraged more time outdoors with larger areas of unacclimatised skin exposed to the sun $[43,44,69]$. Although there was a significant correlation between $\mathrm{UV}_{\text {ery }}$ daily dose and maximum temperature (Figure 2), the comfortable temperatures meant people may not have taken sun protection precautions [71, 72].

During the London Marathon on Sunday, 22 April, tens of thousands of participants and hundreds of thousands of spectators were exposed to the sun for a number of hours around the middle of the day when $\mathrm{UV}_{\text {ery }}$ is highest [46], and 2 SED would be exceeded in $30 \mathrm{~min}$. On the May Day Bank Holiday weekend of 5-7 May, the fine weather would have encouraged outdoor activities [36]. On 7 May 2018, 2 SED would be exceeded in $25 \mathrm{~min}$ around 12 noon. For both of 


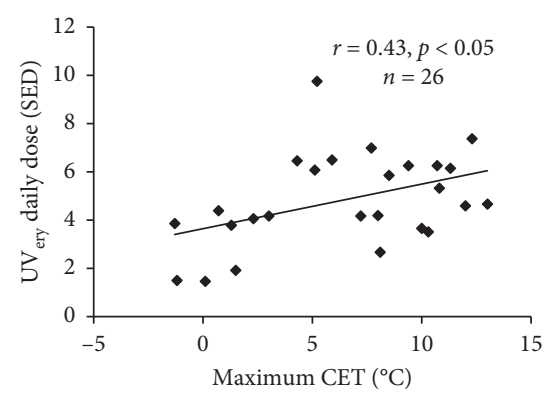

(a)

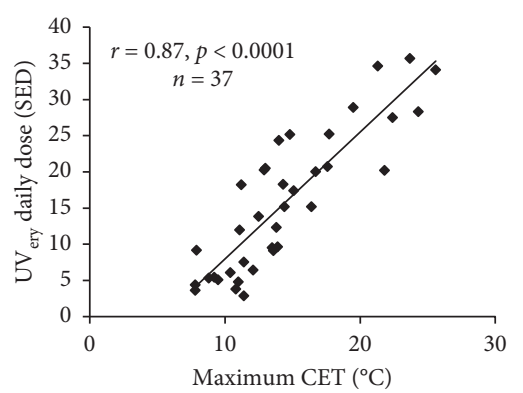

(b)

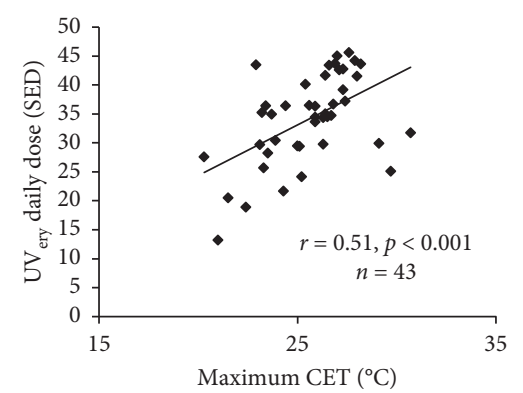

(c)

FIGURE 2: Relationship between erythema effective UV ( $\left.\mathrm{UV}_{\text {ery }}\right)$ daily dose in SED and maximum Central England Temperature (CET) per day for (a) 23 Feb-20 Mar 2019 (Beast from the East period); (b) 1 Apr-7 May 2019 (Spring); (c) 26 Jun-7 Aug 2019 (Heat-Wave). Pearson's correlation coefficient shows a significant positive correlation between these values for all three periods with $p<0.05$. Number of days $(n)$ is shown.

these events, a combination of high environmental availability of $\mathrm{UV}_{\text {ery }}$ along with $>30 \%$ of body area $[43,44]$ being exposed to the sun due to warm weather could have resulted in excess solar $\mathrm{UV}_{\text {ery }}$ exposure.

The implications of these likely $\mathrm{UV}_{\text {ery }}$ exposures for public health are significant. An increase in $U_{\text {ery }}$ exposure may result in improved vitamin D status [21], particularly when ambient temperature allows large areas of skin to be exposed to the sun. This may be a particular benefit for those with darker skin colour (Fitzpatrick skin types IV-VI) for which vitamin $\mathrm{D}$ generation requires higher $\mathrm{UV}_{\text {ery }}$ doses $[73,74]$. However, excess solar $U_{\text {ery }}$ exposure can cause sunburn and increased risk of skin cancers [18].

The high variability of UV and temperature in spring 2018, even without any low ozone events, has demonstrated that it is important that solar radiation is monitored as well as temperature so that appropriate public health advice can be given. A combined temperature and UV impact-based framework and alert system that accounts for temperature extremes at any time of year may be of benefit to the public. This is particularly the case in spring when specific and timely guidance on sun protection, including for events such as the London Marathon, is needed.

3.5. June-August 2018. $\mathrm{UV}_{\text {ery }}$ daily doses were high during the 2018 summer Heat Wave (Figure 1) - on average 25.4\% above the long-term average $(+0.8 \mathrm{SD})$. On 26 July, the maximum temperature reached $30.7^{\circ} \mathrm{C}, 41 \%$ (2.9 SD) above the long-term average. On 7 July 2018 the $\mathrm{UV}_{\text {ery }}$ daily dose at Chilton reached $45.6 \mathrm{SED},+73 \%(+2.4 \mathrm{SD})$, and 2 SED would be exceeded in $20 \mathrm{~min}$ around mid-day. The $\mathrm{UV}_{\text {ery }}$ daily doses on 7 July and 1 August (35.3 SED) were the highest on these respective days since the start of the dataset in 1991. From 26 June to 15 July the UVI consistently reached high levels of 7-8; from 16 July to 7 August the maximum UVI was 5-7 except for 29 July (maximum UVI 3). Figure 1 shows that although on average (1991-2017) the peak $U_{\text {ery }}$ daily dose at Chilton occurs in late June and the peak temperature occurs around 1 month later towards the end of July, in 2018 both variables had their peak in July during the heat-wave.
The public health implications for solar UV exposure during the heat-wave are complex. In general, it is likely that when it is warmer, British people spend more time in the sun [75], particularly with many large outdoor public events occurring in summer months. In warm, fine weather people are likely to have a higher proportion of skin exposed to the sun [43, 44]; British people are generally favourable towards a tan and are not always careful when it comes to sun exposure [71, 72]. This may have increased vitamin D generation [76] and particularly benefited those with darker skin types (Fitzpatrick skin types IV-VI) [73, 74]. However, it is also likely that more people took sun protection precautions since there is a public perception that a risk of sunburn is greater when it is hotter [38, 77]. The significant, although moderate, correlation between $\mathrm{UV}_{\text {ery }}$ daily dose and maximum temperature (Figure 2) may have encouraged people to protect themselves from overexposure to the sun on days when the $\mathrm{UV}_{\text {ery }}$ was higher. In addition, the long duration of the heat-wave and its publicity by the media was also likely to encourage people to take steps to protect themselves [75].

While in general people are likely to have been outside for longer and more regularly, the health implications of this in terms of UV exposure are difficult to determine with good confidence as these are highly dependent on behaviour and vary between different sociodemographic groups. This can be illustrated using young people as an example. University students in England normally have summer holidays from June to September, covering the entire 2018 heat-wave period. They like to spend time outdoors when it is hotter and engage in sport and sunbathing $[38,70]$ but often feel that their sun protection practice may not be sufficiently thorough [38, 70]. Without increased sun protection or avoidance, elevated $\mathrm{UV}_{\text {ery }}$ may have resulted in a $25 \%$ increase of their $\mathrm{UV}_{\text {ery }}$ exposure during the heat-wave compared with the same period in 1991-2017. In contrast, UK children of school age normally remain in school with time outdoors limited by classroom lessons until the start of their summer holidays at the end of July. By this time in 2018, the heat-wave with elevated temperature and UV would have been nearing its end. For nursery children, although the 


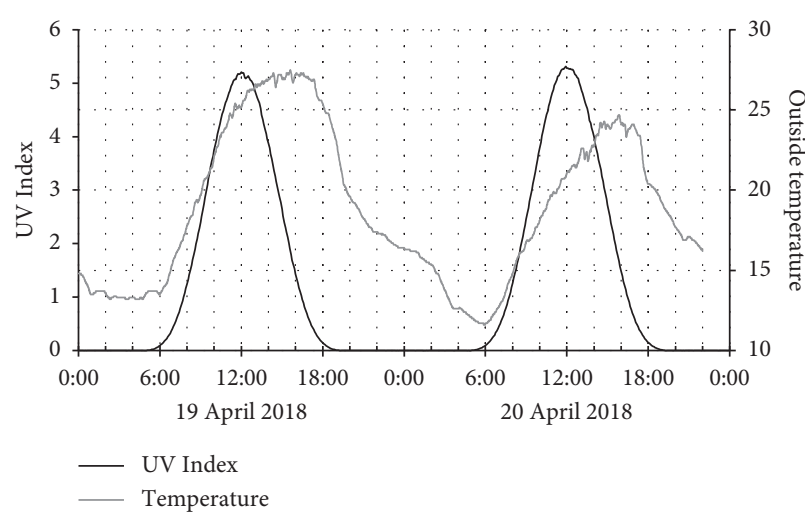

(a)

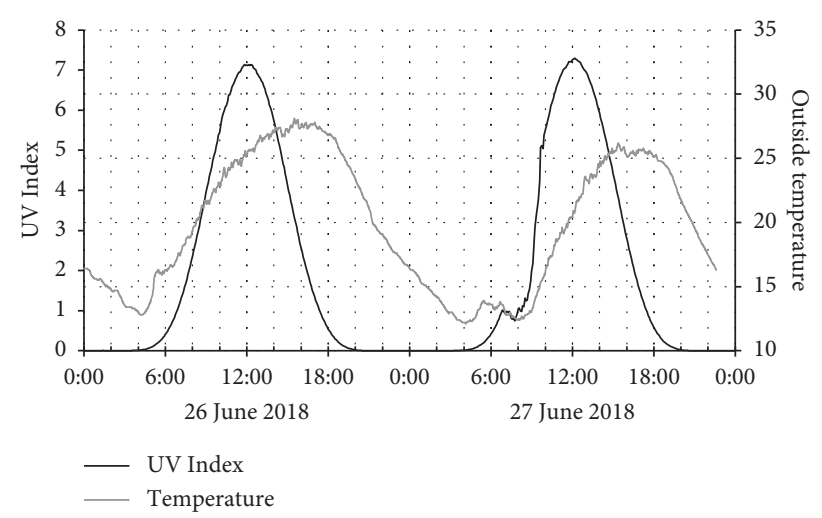

(b)

Figure 3: UV Index and temperature as measured by a colocated Davis Vantage Pro2 Weather Station at Chilton for 19-20 April 2018 and 26-27 June 2018.

good weather may have encouraged more time outdoors, there are clear sun protection policies recommended for all UK childcare establishments which, if followed, should mean nursery children would be unlikely to have higher $\mathrm{UV}_{\text {ery }}$ exposure during the heat-wave of 2018.

Although there was a moderate correlation between temperature and UV when whole days were compared (Figure 2), this relationship should be treated with caution. Figure 3 shows the variation in ambient temperature and UVI (dose rate) at Chilton within a day for two clear days in spring 2018 and the summer heat-wave. The temperature used here is local to Chilton and is not the CET. It is evident that although there is a relationship between UVI and temperature over the course of the day, temperature is not a good predictor of UVI. At 5pm on 19 April 2018, the temperature was $27^{\circ} \mathrm{C}$, and the UVI was 1; on 27 June 2018, around mid-day, the temperature was $20^{\circ} \mathrm{C}$, and the UVI was 7. In addition, the peak daily temperature occurs around 4 hours after the maximum UVI.

Consideration of the health benefits of other solar spectral regions, such as body clock regulation and cardiovascular health $[27,28,30-32]$, would also be worthwhile.

It is important that solar radiation and temperature are monitored during the summer. This analysis has shown that although on average solar UV doses are greatest at the end of June, extreme weather conditions can shift the highest solar UV doses to later in the year. An impact-based UV alert system with targeted and timely advice for different groups of people, taking account of both environmental variables, may be of benefit to the public $[27,78]$.

3.6. Limitations. The limitations of this study include the fact that health impacts were not directly measured and had to be inferred from previously published literature. The behaviour and exposure of individuals were assessed using temperature as a proxy for behaviour. This study also only looks at extreme events in a single year and focuses on South East England. The use of Pearson's correlation analysis was considered the best choice in this context but has limitations due to the small sample sizes and the potential lack of normality in the data.

\section{Conclusions}

$\mathrm{UV}_{\text {ery }}$ daily doses during extreme cold and hot weather episodes of 2018 in Chilton, South East England, sometimes reached extreme values outside the full range observed on particular days since the start of the dataset in 1991.

During April-May 2018, unseasonably high temperatures coincided with high $\mathrm{UV}_{\text {ery }}$ on some days, although the Hot Weather Plan was not triggered as this was outside the alerting period. The potential health impacts of $U_{\text {ery }}$ exposure were significant. For most of the period of the heatwave in summer $2018 \mathrm{UV}_{\text {ery }}$ daily doses were elevated. The implications for health outcomes related to solar UV exposure were complex and dependent on specific sociodemographic variables such as skin colour.

Analysis of $\mathrm{UV}_{\text {ery }}$ in the context of extreme cold and hot temperatures in 2018 has shown that an impact-based alert system and balanced public health advice regarding sun exposure as well as temperature would be of benefit throughout the year and particularly in spring and summer. In addition, a comparison of health outcomes with solar radiation data may increase the evidence base for the impacts of solar UV radiation on health and refine public health advice going forward.

\section{Data Availability}

Erythema effective UV irradiance data are available under the Open Government Licence (OGL): http://www.nationalarchives.gov.uk/doc/open-government-licence/version/3/. UV Index data (back to 2010) are available online in graphical format: https://uk-air.defra.gov.uk/data/uv-index-graphs. Maximum CET data are available from the UK Met Office: https:// www.metoffice.gov.uk/hadobs/hadcet/data/download.html.

\section{Conflicts of Interest}

The authors declare that there are no conflicts of interest. 


\section{References}

[1] IPCC, IPCC, 2014: Climate Change 2014: Synthesis Report. Contribution of Working Groups I, II, and III to the Fifth Assessment Report of the Intergovernmental Panel on Climate Change, IPCC, Geneva, Switzerland, 2014.

[2] G. A. Meehl and C. Tebaldi, "More intense, more frequent, and longer lasting heat waves in the 21st century," Science, vol. 305, no. 5686, pp. 994-997, 2004.

[3] P. A. Stott, D. A. Stone, and M. R. Allen, "Human contribution to the European heatwave of 2003," Nature, vol. 432, no. 7017, pp. 610-614, 2004.

[4] D. Bernie, UKCP18 Derived Projections of Future Climate over the UK, Met Office, Exeter, UK, 2018.

[5] NASA, G. S. Center, and G. a. S. V. Studio, Shifting Distribution of Summer Temperature Anomalies, NASA, G. S. Center, and G. a. S. V. Studio, Washington, DC, USA, 2018, https://svs.gsfc.nasa.gov/3975.

[6] IPCC, "IPCC, 2014: summary for policymakers," in Climate Change 2014: Impacts, Adaptation, and Vulnerability. Part A: Global and Sectoral Aspects. Contribution of Working Group II to the Fifth Assessment Report of the Intergovernmental Panel on Climate Change, pp. 1-32, Cambridge University Press, Cambridge, UK, 2014.

[7] D. Mitchell, "Attributing human mortality during extreme heat waves to anthropogenic climate change," Environmental Research Letters, vol. 11, no. 7, Article ID 074006, 2016.

[8] S. Vardoulakis, K. Dear, S. Hajat, C. Heaviside, B. Eggen, and A. J. McMichael, "Comparative assessment of the effects of climate change on heat- and cold-related mortality in the United Kingdom and Australia," Environmental Health Perspectives, vol. 122, no. 12, pp. 1285-1292, 2014.

[9] S. Hajat, S. Vardoulakis, C. Heaviside, and B. Eggen, "Climate change effects on human health: projections of temperaturerelated mortality for the UK during the 2020s, 2050s and 2080s," Journal of Epidemiology and Community Health, vol. 68, no. 7, pp. 641-648, 2014.

[10] B. G. Armstrong, Z. Chalabi, B. Fenn et al., "Association of mortality with high temperatures in a temperate climate: England and Wales," Journal of Epidemiology \& Community Health, vol. 65, no. 4, pp. 340-345, 2011.

[11] V. Abrahamson, J. Wolf, I. Lorenzoni et al., "Perceptions of heatwave risks to health: interview-based study of older people in London and Norwich, UK," Journal of Public Health, vol. 31, no. 1, pp. 119-126, 2008.

[12] S. Hajat, R. S. Kovats, and K. Lachowycz, "Heat-related and cold-related deaths in England and Wales: who is at risk?," Occupational and Environmental Medicine, vol. 64, no. 2, pp. 93-100, 2007.

[13] R. S. Kovats and L. E. Kristie, "Heatwaves and public health in Europe," European Journal of Public Health, vol. 16, no. 6, pp. 592-599, 2006.

[14] R. S. Kovats, S. Hajat, and P. Wilkinson, "Contrasting patterns of mortality and hospital admissions during hot weather and heat waves in Greater London, UK," Occupational and Environmental Medicine, vol. 61, no. 11, pp. 893-898, 2004.

[15] M. F. Holick, "Biological effects of sunlight, ultraviolet radiation, visible light, infrared radiation and vitamin $\mathrm{D}$ for health," Anticancer Research, vol. 36, no. 36, pp. 1345-1356, 2016.

[16] J. Moan, A Dahlback, Z Lagunova, E Cicarma, and AC Porojnicu, "Solar radiation, vitamin D and cancer incidence and mortality in Norway," Anticancer Research, vol. 29, no. 29, pp. 3501-3509, 2009.
[17] V. Bouvard, R. Baan, K. Straif et al., "A review of human carcinogens-Part B: biological agents," The Lancet Oncology, vol. 10, no. 4, pp. 321-322, 2009.

[18] J. Reichrath, Sunlight, Vitamin D and Skin Cancer, Landes Bioscience/Springer Science+Business Media, Austin, TX, USA, 2008.

[19] R. Lucas, Solar Ultraviolet Radiation: Global Burden of Disease from Solar Ultraviolet Radiation, WHO, Geneva, Switzerland, 2006.

[20] AGNIR, "Health Effects from ultraviolet radiation (report of an advisory group on non-ionising radiation)," Documents of the NRPB, vol. 13, 2002.

[21] SACN, Vitamin D and Health, Public Health England, London, UK, 2016, https://assets.publishing.service.gov.uk/government/ uploads/system/uploads/attachment_data/file/537616/SACN_ Vitamin_D_and_Health_report.pdf.

[22] AGNIR, Ultraviolet Radiation, Vitamin D and Health (Report of the Independent Advisory Group on Non-ionising Radiation), Public Health England, London, UK, 2017, https:// assets.publishing.service.gov.uk/government/uploads/system/ uploads/attachment_data/file/620184/UV_Radiation_Vitamin_ D_Health.pdf.

[23] H. Van der Rhee, E. de Vries, C. Coomans, P. van de Velde, and J. W. Coebergh, "Sunlight: for better or for worse? A review of positive and negative effects of sun exposure," Cancer Research Frontiers, vol. 2, no. 2, pp. 156-183, 2016.

[24] M. F. Holick, "Sunlight and vitamin D for bone health and prevention of autoimmune diseases, cancers, and cardiovascular disease," The American Journal of Clinical Nutrition, vol. 80, no. 6, pp. 1678S-1688S, 2004.

[25] A. R. Young and S. L. Walker, "UV radiation, vitamin D and human health: an unfolding controversy introduction," Photochemistry and Photobiology, vol. 81, no. 6, pp. 12431245, 2005.

[26] R. B. Weller, "The health benefits of UV radiation exposure through vitamin $\mathrm{D}$ production or non-vitamin D pathways. Blood pressure and cardiovascular disease," Photochemical \& Photobiological Sciences, vol. 16, no. 3, pp. 374-380, 2017.

[27] M. Feelisch, V. Kolb-Bachofen, D. Liu et al., "Is sunlight good for our heart?" European Heart Journal, vol. 31, no. 9, pp. 1041-1045, 2010.

[28] D. Liu, B. O. Fernandez, A. Hamilton et al., "UVA irradiation of human skin vasodilates arterial vasculature and lowers blood pressure independently of nitric oxide synthase," Journal of Investigative Dermatology, vol. 134, no. 7 , pp. 1839-1846, 2014.

[29] S. Geldenhuys, P. H. Hart, R. Endersby et al., "Ultraviolet radiation suppresses obesity and symptoms of metabolic syndrome independently of vitamin D in mice fed a high-fat diet," Diabetes, vol. 63, no. 11, pp. 3759-3769, 2014.

[30] A. Juzeniene and J. Moan, "Beneficial effects of UV radiation other than via vitamin D production," Dermato-endocrinology, vol. 4, no. 2, pp. 109-117, 2012.

[31] A. Juzeniene, "Solar radiation and human health," Reports on Progress in Physics, vol. 74, no. 6, Article ID 066701, 2011.

[32] G. Holliman, "Ultraviolet radiation-induced production of nitric oxide: a multi-cell and multi-donor analysis," Scientific Reports, vol. 7, no. 1, Article ID 11105, 2017.

[33] E. de Vries, I. Soerjomataram, S. Houterman, M. W. J. Louwman, and J. W. W. Coebergh, "Decreased risk of prostate cancer after skin cancer diagnosis: a protective role of ultraviolet radiation?" American Journal of Epidemiology, vol. 165, no. 8, pp. 966-972, 2007. 
[34] C. A. Baggerly, R. E. Cuomo, C. B. French et al., "Sunlight and vitamin D: necessary for public health," Journal of the American College of Nutrition, vol. 34, no. 4, pp. 359-365, 2015.

[35] P. G. Lindqvist, E. Epstein, K. Nielsen, M. Landin-Olsson, C. Ingvar, and H. Olsson, "Avoidance of sun exposure as a risk factor for major causes of death: a competing risk analysis of the Melanoma in Southern Sweden cohort," Journal of Internal Medicine, vol. 280, no. 4, pp. 375-387, 2016.

[36] K. A. Baczynska, M. Khazova, and J. B. O’Hagan, "Sun exposure of indoor workers in the UK-survey on the time spent outdoors," Photochemical \& Photobiological Sciences, vol. 18, no. 1, pp. 120-128, 2018.

[37] C. C. Wong, W. Liu, P. Gies, and R. Nixon, "Think UV, not heat!," Australasian Journal of Dermatology, vol. 56, no. 4, pp. 275-278, 2014.

[38] F. Jones, P. Harris, and C. Chrispin, "Catching the sun: an investigation of sun-exposure and skin protective behaviour," Psychology, Health \& Medicine, vol. 5, no. 2, pp. 131-141, 2000.

[39] C. E. Williamson, R. G. Zepp, R. M. Lucas et al., "Solar ultraviolet radiation in a changing climate," Nature Climate Change, vol. 4, no. 6, pp. 434-441, 2014.

[40] A. F. Bais, R. L. McKenzie, G. Bernhard et al., "Ozone depletion and climate change: impacts on UV radiation," Photochemical \& Photobiological Sciences, vol. 14, no. 1, pp. 19-52, 2015.

[41] A. H. Butler, J. S. Daniel, R. W. Portmann et al., "Diverse policy implications for future ozone and surface UV in a changing climate," Environmental Research Letters, vol. 11, no. 6, Article ID 064017, 2016.

[42] J. F. Bornman, P. W. Barnes, S. A. Robinson, C. L. Ballaré, S. D. Flint, and M. M. Caldwell, "Solar ultraviolet radiation and ozone depletion-driven climate change: effects on terrestrial ecosystems," Photochemical \& Photobiological Sciences, vol. 14, no. 1, pp. 88-107, 2015.

[43] N. Chubarova and Y. Zhdanova, "Ultraviolet resources over northern eurasia," Journal of Photochemistry and Photobiology B: Biology, vol. 127, pp. 38-51, 2013.

[44] J. Guzikowski, J. Krzyścin, A. Czerwińska, and W. Raszewska, "Adequate vitamin D3 skin synthesis versus erythema risk in the Northern Hemisphere midlatitudes," Journal of Photochemistry and Photobiology B: Biology, vol. 179, pp. 54-65, 2018.

[45] A. F. McKinlay and B. L. Diffey, "A reference action spectrum for ultraviolet induced erythema in human skin," Computers and Industrial Engineering Journal, vol. 6, no. 1, pp. 17-22, 1987.

[46] B. L. Diffey, "Sources and measurement of ultraviolet radiation," Methods, vol. 28, no. 1, pp. 4-13, 2002.

[47] A. J. Samanek, E. J. Croager, P. Gies et al., "Estimates of beneficial and harmful sun exposure times during the year for major Australian population centres," Medical Journal of Australia, vol. 184, no. 7, pp. 338-341, 2006.

[48] I. Medhaug, J. A. Olseth, and J. Reuder, "UV radiation and skin cancer in Norway," Journal of Photochemistry and Photobiology B: Biology, vol. 96, no. 3, pp. 232-241, 2009.

[49] P. Den Outer, H. Slaper, and R. Tax, "UV radiation in The Netherlands: assessing long-term variability and trends in relation to ozone and clouds," Journal of Geophysical Research: Atmospheres, vol. 110, no. D2, 2005.

[50] J.-M. Cadet, H. Bencherif, D. J. du Preez et al., "Solar UV radiation in saint-denis, La réunion and cape town, South Africa: 10 years climatology and human exposure assessment at altitude," Atmosphere, vol. 10, no. 10, p. 589, 2019.
[51] R. Hooke and M. Higlett, "Temperature correction of historic erythema effective solar UV data resulting in a continuous 25year data set at Chilton, UK," Radiation Protection Dosimetry, vol. 175, no. 3, pp. 363-367, 2016.

[52] R. J. Hooke, M. P. Higlett, N. Hunter, and J. B. O'Hagan, "Long term variations in erythema effective solar UV at Chilton, UK, from 1991 to 2015," Photochemical \& Photobiological Sciences, vol. 16, no. 11, pp. 1596-1603, 2017.

[53] D. S. Berger, "The sunburning ultraviolet meter: design and performance," Photochemistry and Photobiology, vol. 24, no. 6, pp. 587-593, 1976.

[54] USNO, US. Naval Observatory Website, USNO, Washington, DC, USA, 2016, http://aa.usno.navy.mil/data/docs/RS_OneYear.php.

[55] WHO, Global Solar UV Index: A Practical Guide, WHO, Geneva, Switzerland, 2002.

[56] PHE, UV Index Graphs, PHE, London, UK, 2016, http://ukair.defra.gov.uk/data/uv-index-graphs.

[57] Met Office, Met Office Hadley Centre Central England Temperature Data, Met Office, Exeter, UK, 2018, https://www. metoffice.gov.uk/hadobs/hadcet/data/download.html.

[58] D. E. Parker, T. P. Legg, and C. K. Folland, "A new daily central England temperature series, 1772-1991," International Journal of Climatology, vol. 12, no. 4, pp. 317-342, 1992.

[59] Met Office, Met Office Hadley Centre Observations Datasets, Met Office, Exeter, UK, 2018, https://www.metoffice.gov.uk/ hadobs/hadcet/index.html.

[60] A. F. Bais, "Environmental effects of ozone depletion, UV radiation and interactions with climate change: UNEP Environmental Effects Assessment Panel, update 2017," Photochemical \& Photobiological Sciences, vol. 17, no. 2, pp. 127-179, 2018.

[61] DEFRA, "Baseline measurement and analysis of UK ozone and UV," Defra Annual Report Contribution ED45367, DEFRA, London, UK, 2012.

[62] PHE, The Cold Weather Plan for England, PHE, London, UK, 2018.

[63] PHE, Heatwave Plan for England, PHE, London, UK, 2018.

[64] G. Masato, "Improving the health forecasting alert system for cold weather and heat-waves in England: a proof-of-concept using temperature-mortality relationships," PLoS One, vol. 10, no. 10, Article ID e0137804, 2015.

[65] Met Office, Weather Summaries, Met Office, Exeter, UK, 2018, https://www.metoffice.gov.uk/climate/uk/summaries/2018.

[66] Met Office, March Statistics May Challenge Your Perception, Met Office, Exeter, UK, 2019, https://www.metoffice.gov.uk/ news/releases/2018/march-statistics.

[67] K. Grandahl, P. Eriksen, K. S. Ibler, J. P. Bonde, and O. S. Mortensen, "Measurements of solar ultraviolet radiation exposure at work and at leisure in danish workers," Photochemistry and Photobiology, vol. 94, no. 4, pp. 807-814, 2018.

[68] P. Höppe, "Different aspects of assessing indoor and outdoor thermal comfort," Energy and Buildings, vol. 34, no. 6, pp. 661-665, 2002.

[69] A. W. Schmalwieser, V. T. Schmalwieser, and S. S. Schmalwieser, "Influence of air temperature on the UV exposure of different body sites due to clothing of young women during daily errands," Photochemistry and Photobiology, vol. 95, no. 4, pp. 1068-1075, 2019.

[70] M. Keil, D. R. Jackson, and M. C. Hort, "The January 2006 low ozone event over the UK," Atmospheric Chemistry and Physics, vol. 7, no. 3, pp. 961-972, 2007.

[71] L. Kirk and S. Greenfield, "Knowledge and attitudes of UK university students in relation to ultraviolet radiation (UVR) 
exposure and their sun-related behaviours: a qualitative study," BMJ Open, vol. 7, no. 3, Article ID e014388, 2017.

[72] British Association of Dermatologists, Home and Away-Brits Getting Sunburnt in the UK and Abroad, British Association of Dermatologists, London, UK, 2017, http://www.bad.org.uk/ News.asp $x$ sitesectionid $=154 \&$ sitesectiontitle $=$ Press + Releases\&originalpath=media\%2fnews\&q=home $\% 20$ and $\%$ 20away\&range $=$ home $\% 20$ and $\% 20$ away $\& \mathrm{l}=0$.

[73] S. J. Felton, M. S. Cooke, R. Kift et al., "Concurrent beneficial (vitamin D production) and hazardous (cutaneous DNA damage) impact of repeated low-level summer sunlight exposures," British Journal of Dermatology, vol. 175, no. 6, pp. 1320-1328, 2016.

[74] A. Webb, A. Kazantzidis, R. Kift, M. Farrar, J. Wilkinson, and L. Rhodes, "Colour counts: sunlight and skin type as drivers of vitamin D deficiency at UK latitudes," Nutrients, vol. 10, no. 4, p. 457, 2018.

[75] J. Palutikof, M. Agnew, and M. Hoar, "Public perceptions of unusually warm weather in the UK: impacts, responses and adaptations," Climate Research, vol. 26, no. 1, pp. 43-59, 2004.

[76] A. R. Webb, R. Kift, M. T. Durkin et al., "The role of sunlight exposure in determining the vitamin $\mathrm{D}$ status of the UK white adult population," British Journal of Dermatology, vol. 163, no. 5, pp. 1050-1055, 2010.

[77] O. B. J. Carter and R. J. Donovan, "Public (Mis)understanding of the UV index," Journal of Health Communication, vol. 12, no. 1, pp. 41-52, 2007.

[78] NICE, Sunlight Exposure: Risks and Benefits, NICE, Ra'anana, Israel, 2016. 